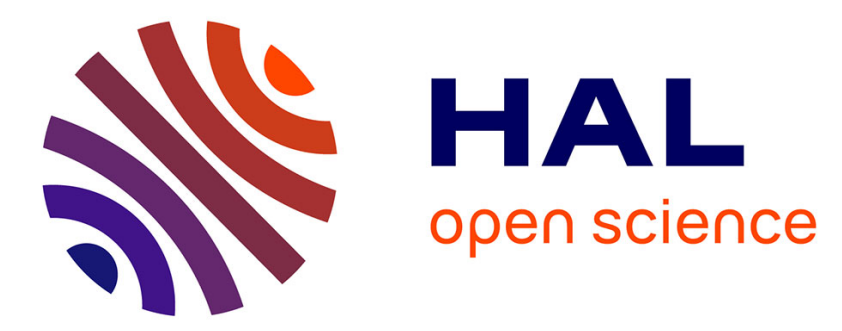

\title{
Charge density study of N-acetyl-L-tyrosine ethyl ester monohydrate derived from CCD area detector data
}

\author{
S. Dahaoui, Christian Jelsch, J. A. K. Howard, C. Lecomte
}

\section{To cite this version:}

S. Dahaoui, Christian Jelsch, J. A. K. Howard, C. Lecomte. Charge density study of N-acetyl-Ltyrosine ethyl ester monohydrate derived from CCD area detector data. Acta Crystallographica Section B: Structural Science [1968-2013], 1999, B55, pp.226-230. 10.1107/S0108768198012099 . hal01710283

\section{HAL Id: hal-01710283 \\ https://hal.science/hal-01710283}

Submitted on 15 Feb 2018

HAL is a multi-disciplinary open access archive for the deposit and dissemination of scientific research documents, whether they are published or not. The documents may come from teaching and research institutions in France or abroad, or from public or private research centers.
L'archive ouverte pluridisciplinaire HAL, est destinée au dépôt et à la diffusion de documents scientifiques de niveau recherche, publiés ou non, émanant des établissements d'enseignement et de recherche français ou étrangers, des laboratoires publics ou privés. 


\title{
Charge density study of $\mathrm{N}$-acetyl-L-tyrosine ethyl ester monohydrate derived from CCD area detector data
}

\author{
S. Dahaoui,${ }^{a} *$ C. Jelsch ${ }^{b}$ J. A. K. Howard ${ }^{a}$ and C. Lecomte ${ }^{b}$ \\ ${ }^{a}$ Crystallography Group, Department of Chemistry, University of Durham, South Road, Durham DH1 3LE, England, \\ and ${ }^{b}$ Laboratoire de Cristallographie et Modélisation des Matériaux Minéraux et Biologiques (LCM $\left.{ }^{3} B\right), E S A C N R S$ \\ 7036, Université Henri Poincaré, Nancy 1, Faculté des Sciences, BP 239, 54506 Vandoeuvre lès Nancy CEDEX, \\ France. E-mail: slimane.dahaoui@durham.ac.uk
}

(Received 23 May 1998; accepted 22 September 1998)

\begin{abstract}
The crystal structure, thermal vibrations and electron density of the peptide $\mathrm{N}$-acetyl-L-tyrosine ethyl ester monohydrate, $\mathrm{C}_{13} \mathrm{H}_{17} \mathrm{NO}_{4} \cdot \mathrm{H}_{2} \mathrm{O}$, have been analysed using single-crystal $\mathrm{X}$-ray diffraction data collected at $110 \mathrm{~K}$ with $\mathrm{Mo} K \alpha$ radiation to a resolution of $(\sin \theta / \lambda)_{\max }=1.1 \AA^{-1}$. A CCD area detector was used to collect 98393 data during one week. A multipolar atom density model was fitted against the 10189 unique data with $I>2 \sigma(I)[R(F)=0.027, w R(F)=0.020$, g.o.f. $=0.65]$ in order to map the valence electron distribution. These deformation densities compare very well with those obtained from conventional diffractometers equipped with scintillation detectors. This work shows that area detectors permit charge density studies in a more routine way than is possible with conventional diffractometers.
\end{abstract}

\section{Introduction}

It is well known that charge density studies need accurate X-ray diffraction measurements and careful data reduction. This step, which requires considerable experimental expertise, is very time consuming when using a conventional diffractometer equipped with a one-point-scintillation detector. Two-dimensional (2D) detectors like CCDs (charge-coupled devices) or imaging plates are widely used in protein crystallography and are becoming more and more popular for routine crystal structure determinations (2-24 h data collection times). However, until recently very few electron density studies have been carried out using 2Ddetector data. The first experiments using conventional $\mathrm{X}$-ray sources and $2 \mathrm{D}$ detectors devoted to charge density studies were discussed in a session of the XI Sagamore conference (August 1997, Prince Albert, Canada) by Coppens (1997) and Pinkerton (1997), and at the BCA Spring Meeting (April 1998, St Andrews, Scotland) by Dahaoui et al. (1998). Other experiments using synchrotron radiation at HASYLAB, Hamburg, Germany, (Koritsanszky et al., 1998) and at the ESRF, Grenoble, France, (Graafsma et al., 1998) have estab- lished the possibility of carrying out accurate measurements for charge density work.

In this paper we discuss the results of one of the first accurate charge density studies obtained from a CCDbased diffractometer: we show that this seven-day data set gives precise details of the charge density which would have needed at least one month of data collection time on a conventional diffractometer.

The results of the study of $N$-acetyl-L-tyrosine ethyl ester monohydrate will be archived in our chargedensity data bank of peptides and related compounds (Pichon-Pesme et al., 1995; Jelsch et al., 1998). Indeed, the fine description of the electron density can be extended to structures of lower resolution by applying the notion of transferability of the charge and density parameters.

\section{Data collection and data reduction analysis}

The crystal structure at room temperature of $N$-acetyl-Ltyrosine ethyl ester monohydrate was first reported by Pieret et al. (1972) $(R=0.107)$ and refined (to $R=$ 0.052 ) by Soriano-García (1993).

A good quality crystal $(0.3 \times 0.2 \times 0.2 \mathrm{~mm})$ was selected for the X-ray diffraction study. A preliminary short and quick data collection on a Siemens SMART CCD-based diffractometer $(50 \mathrm{kV}$ and $40 \mathrm{~mA})$ at room temperature with Mo $K \alpha$ radiation confirmed without ambiguity that it was orthorhombic, space group $P 22_{1} 2_{1}$. This room-temperature data collection was performed as follows: the data covered a sphere of reciprocal space by combining four sets of runs; each set had a different $\varphi$ angle $\left(0,88,180\right.$ and $\left.268^{\circ}\right)$ and each frame covered $0.3^{\circ}$ in $\omega$ for $10 \mathrm{~s}$ exposure time. The crystal-to-detector distance was $4.51 \mathrm{~cm}$. The data were $99 \%$ complete to $55^{\circ} 2 \theta\left[(\sin \theta / \lambda)=0.77 \AA^{-1}\right]$. Crystal decay was monitored by repeating the 50 initial frames at the end of the data collection and analysing the duplicate reflections. Cell parameters $[a=7.3827$ (2), $b$ $=13.1421(4), c=14.5150(4) \AA]$ were retrieved using SMART software (Siemens, 1995) on 411 selected reflections. Data reduction was performed using SAINT 
Table 1 . A summary of the $110 \mathrm{~K} X$-ray data collection strategy

\begin{tabular}{|c|c|c|c|c|c|c|}
\hline Run No. & $2 \theta$ & $\omega_{0}$ & $\varphi$ & $\chi$ & Frames & Time per frame (s) \\
\hline $0 \dagger$ & -29 & -26 & 0 & 54.70 & 909 & 20 \\
\hline $1 \dagger$ & -29 & -21 & 88 & 54.70 & 635 & 20 \\
\hline $2 \dagger$ & -29 & -26 & 0 & 54.70 & 50 & 20 \\
\hline $3 \dagger$ & -29 & -26 & 180 & 54.70 & 909 & 20 \\
\hline $4 \dagger$ & -29 & -21 & 268 & 54.70 & 635 & 20 \\
\hline $5 \dagger$ & -29 & -26 & 0 & 54.70 & 50 & 20 \\
\hline 12 & -29 & -26 & 0 & 54.70 & 909 & 20 \\
\hline 13 & -29 & -21 & 45 & 54.70 & 635 & 20 \\
\hline 14 & -29 & -26 & 0 & 54.70 & 50 & 20 \\
\hline 15 & -29 & -26 & 135 & 54.70 & 909 & 20 \\
\hline 16 & -29 & -21 & 225 & 54.70 & 635 & 20 \\
\hline 17 & -29 & -26 & 0 & 54.70 & 50 & 20 \\
\hline 18 & +29 & -26 & 0 & 54.70 & 200 & 20 \\
\hline 19 & -74 & -66 & 0 & 54.70 & 901 & 40 \\
\hline 20 & -74 & -66 & 90 & 54.70 & 901 & 40 \\
\hline 21 & -74 & -66 & 180 & 54.70 & 901 & 40 \\
\hline 22 & -74 & -66 & 270 & 54.70 & 901 & 40 \\
\hline 23 & -74 & -66 & 45 & 54.70 & 451 & 40 \\
\hline 24 & -74 & -66 & 135 & 54.70 & 451 & 40 \\
\hline 25 & -74 & -66 & 225 & 54.70 & 451 & 40 \\
\hline 26 & -74 & -66 & 315 & 54.70 & 451 & 40 \\
\hline
\end{tabular}

$\dagger$ Frame collection repeated twice.

software (Siemens, 1995), which corrects for Lorentz and polarization effects, and decay. The structure was solved by direct methods using SHELXS86 (Sheldrick, 1990) and refined by a least-squares method on $F^{2}$ using SHELXL93 (Sheldrick, 1993). All $\mathrm{H}$ atoms (including the $\mathrm{H}$ atoms of the water molecule) were located by difference Fourier synthesis. The refined parameters included anisotropic mean-square displacements for non- $\mathrm{H}$ atoms, and positions and isotropic mean-square displacements for $\mathrm{H}$ atoms $\left[R\left(F^{2}\right)=0.038\right]$. Details of the experiment, fractional coordinates, displacement parameters, bond distances and angles have been deposited as supplementary material. $\dagger$

As the room-temperature crystal structure was of good quality and as intense diffraction was observed for high $2 \theta$ values, this crystal was deemed suitable for a charge density study. The crystal was cooled to $110 \mathrm{~K}$ with an Oxford Cryostream $\mathrm{N}_{2}$ open-flow cryostat and the unit-cell parameters were refined. The ASTRO program (Siemens, 1995) was then used to check the completeness to a given resolution with the required level of redundancy. Then two batches of data were collected: the first one at low $\theta$ covered the whole sphere of reciprocal space up to $55^{\circ}$ in $2 \theta$ and the second (highorder) batch was $93.8 \%$ complete to at least $109^{\circ}$ in $2 \theta$. Low-angle frames were collected for $20 \mathrm{~s}$ and high-angle frames for $40 \mathrm{~s}$ in order to increase the precision of the measurements and to compensate for the decrease of the diffracted intensity at high $2 \theta$ values. Each run had a different $\varphi$ angle and each frame covered $0.2^{\circ}$ in $\omega$ in

† Supplementary data for this paper are available from the IUCr electronic archives (Reference: AN0551). Services for accessing these data are described at the back of the journal. order to obtain accurate intensity profiles. The first loworder runs were repeated because the valence electron density information is carried by the low-angle reflections. The complete data-collection strategy is summarized in Table 1. A total of 9764 frames were collected over a period of seven days.

The unit cell was then refined using 512 reflections of the low-angle batch only, with a threshold $I / \sigma(I)>50$, and with a minimum and maximum resolution of 0.5 and $0.8 \AA^{-1}$, respectively [cell parameters obtained: $a=$ $7.235(2), \quad b=13.056$ (4), $c=14.415$ (4) Å]. Data reduction was performed as for the room-temperature data for Lorentz and polarization effects [SAINT; Siemens (1995)]. The procedure of integration of frames is described by Kabsch (1993). Each three-dimensional peak profile was placed inside a three-dimensional box of a given size. The size of the box is constant for all lowangle frames and 1.5 times larger in terms of peak width ( $x$ and $y$ directions) for high-order frames because of the $K \alpha_{1}$ and $K \alpha_{2}$ splitting. Although absorption is negligible with Mo $K \alpha$ radiation $\left(\mu=0.098 \mathrm{~mm}^{-1}\right)$, the intensities have been corrected for beam inhomogeneity and decay using SADABS (Sheldrick, 1996).

Of the 98393 integrated reflections 610 were measured only once and 97783 were multiple measurements which, on averaging using SORTAV (Blessing, 1987), gave 14787 unique structure-factor amplitudes to a resolution of $(\sin \theta / \lambda)_{\max }=1.1 \AA^{-1}$. Internal agreement factors are $R_{\text {int }}\left(F^{2}\right)=0.027$ and $w R\left(F^{2}\right)=0.032\left[w=1 / \sigma^{2}\left(F^{2}\right)\right]$. No problem from $\lambda / 2$ contamination appeared in our data set and no systematically absent reflections were observed, in contrast to the case discussed in detail by Kirschbaum $e t$ al. (1997). 
Table 2. Bond-vibration analysis

$Z^{2}$ is the squared amplitude in the bond direction $(A-B)$ and $\Delta Z^{2}$ is the difference for the atom pair. $\left\langle X^{2}\right\rangle$ is the mean-square amplitude perpendicular to the bond. The bond lengths have been corrected for rigid motion (Busing \& Levy, 1964).

\begin{tabular}{|c|c|c|c|c|c|c|c|}
\hline Atom $A$ & Atom $B$ & $Z_{A}^{2}$ & $Z_{B}^{2}$ & $\Delta Z^{2}$ & $\left\langle X_{A}^{2}\right\rangle$ & $\left\langle X_{B}^{2}\right\rangle$ & $\begin{array}{l}\text { Corrected } \\
\text { length }(\AA)\end{array}$ \\
\hline $\mathrm{CA}$ & $\mathrm{N}$ & 0.0112 & 0.0109 & -0.0004 & 0.0110 & 0.0132 & 1.4452 \\
\hline $\mathrm{C}$ & $\mathrm{O}$ & 0.0129 & 0.0130 & 0.0001 & 0.0129 & 0.0191 & 1.2415 \\
\hline $\mathrm{C}$ & $\mathrm{N}$ & 0.0127 & 0.0124 & -0.0004 & 0.0130 & 0.0124 & 1.3473 \\
\hline $\mathrm{C}$ & $\mathrm{C} 1$ & 0.0119 & 0.0124 & 0.0005 & 0.0135 & 0.0251 & 1.5125 \\
\hline $\mathrm{C} 2$ & $\mathrm{O} 1$ & 0.0105 & 0.0106 & 0.0002 & 0.0126 & 0.0250 & 1.2210 \\
\hline $\mathrm{C} 2$ & $\mathrm{O} 2$ & 0.0112 & 0.0116 & 0.0004 & 0.0123 & 0.0166 & 1.3253 \\
\hline $\mathrm{C} 2$ & $\mathrm{CA}$ & 0.0092 & 0.0096 & 0.0004 & 0.0133 & 0.0119 & 1.5302 \\
\hline CD1 & $\mathrm{CG}$ & 0.0131 & 0.0127 & -0.0004 & 0.0162 & 0.0125 & 1.3987 \\
\hline CD1 & CE1 & 0.0123 & 0.0122 & 0.0000 & 0.0167 & 0.0163 & 1.3959 \\
\hline C3 & $\mathrm{O} 2$ & 0.0098 & 0.0094 & -0.0005 & 0.0219 & 0.0177 & 1.4530 \\
\hline C3 & $\mathrm{C} 4$ & 0.0160 & 0.0163 & 0.0003 & 0.0188 & 0.0315 & 1.5051 \\
\hline $\mathrm{CB}$ & $\mathrm{CA}$ & 0.0122 & 0.0121 & -0.0001 & 0.0143 & 0.0106 & 1.5410 \\
\hline $\mathrm{CB}$ & $\mathrm{CG}$ & 0.0112 & 0.0109 & -0.0003 & 0.0148 & 0.0133 & 1.5139 \\
\hline $\mathrm{CZ}$ & CE1 & 0.0105 & 0.0106 & 0.0001 & 0.0155 & 0.0171 & 1.3971 \\
\hline $\mathrm{CZ}$ & $\mathrm{OH}$ & 0.0109 & 0.0112 & 0.0003 & 0.0153 & 0.0222 & 1.3723 \\
\hline CE2 & $\mathrm{CZ}$ & 0.0116 & 0.0118 & 0.0002 & 0.0213 & 0.0148 & 1.3960 \\
\hline $\mathrm{CD} 2$ & CE2 & 0.0119 & 0.0119 & 0.0000 & 0.0190 & 0.0212 & 1.3956 \\
\hline $\mathrm{CD} 2$ & $\mathrm{CG}$ & 0.0116 & 0.0114 & -0.0002 & 0.0191 & 0.0131 & 1.3946 \\
\hline
\end{tabular}

\section{Refinement}

The charge density model was obtained from the multipole model (MOLLY; Hansen \& Coppens, 1978). In addition to a scale factor and the conventional atomic and displacement parameters, several atomic density deformation parameters were refined. The electron density of an atom is described by

$$
\begin{aligned}
\rho_{\text {atom }}(\mathbf{r})= & \rho_{\text {core }}(r)+P_{v} \kappa^{3} \rho_{v}(\kappa r) \\
& +\sum_{l=0}^{l_{\max }} \kappa^{\prime 3} R_{l}\left(\kappa^{\prime} r\right) \sum_{m=0}^{l} P_{l m \pm} y_{l m \pm}(\theta, \varphi),
\end{aligned}
$$

where $\rho_{\text {core }}$ and $\rho_{v}$ are the spherically averaged core and valence electron density, $y_{l m}$ represents the multipolar spherical harmonic angular functions in real form, $R_{l}$ represents the Slater-type radial functions and $\kappa, \kappa^{\prime}$ are the contraction/expansion coefficients of the perturbed density. The coordinates $r, \theta$ and $\varphi$ refer to the local atom-centred Cartesian axes. $P_{v}$ is the refined valence population parameter, which gives the charge transfer with respect to the number $N_{v}$ of electrons in the valence orbitals of the atom; the net charge is $\left(N_{v}-P_{v}\right) . P_{l m}$ are the multipolar population parameters.

The real and imaginary dispersion corrections to the form factors (Creagh \& McAuley, 1992) were used in the structure-factor calculations. First a high-order (HO) refinement was performed, using 3060 reflections with $0.9<\sin \theta / \lambda<1.1 \AA^{-1}$ and $I>2 \sigma(I)$, to obtain the best estimate of the atomic positions and displacement parameters of the non-H atoms. All $x y z$ and $U^{i j}$ were refined. Convergence was achieved at $R(F)=0.064$, $w R(F)=0.067$ and g.o.f. $=0.68$. At the end of the $\mathrm{HO}$ refinement, the rigid-bond test (Hirshfeld, 1976) was applied for non-H atoms: the test gives hopeful results with a maximum discrepancy $\Delta Z^{2}=7 \times 10^{-4} \AA^{2}$ for the $\mathrm{C} 2-\mathrm{O} 1$ and $\mathrm{C} 3-\mathrm{O} 2$ bonds. The positional and isotropic displacement parameters of the $\mathrm{H}$ atoms were refined at low angle $\left(\sin \theta / \lambda<0.5 \AA^{-1}\right)$, then the $\mathrm{H}$ atoms were shifted along the $\mathrm{Csp} p^{3}-\mathrm{H}, \mathrm{Csp}^{2}-\mathrm{H}, \mathrm{OW}-$ $\mathrm{H}$ and $\mathrm{N}-\mathrm{H}$ bond vectors to average bond-distance values determined from neutron-diffraction studies (Allen, 1986) of 1.085, 1.076, 0.96 and $1.032 \AA$, respectively. These distances were kept fixed during all further refinements. The multipolar refinement was carried out using all 10189 reflections with $I>2 \sigma(I)$ with the following strategy: scale factor, $P_{v}$ then $\kappa, P_{v}$ and $\kappa, P_{l m}$ then $\kappa^{\prime}, x y z$ and $U^{i j}$ for the non-H atoms. Then all the parameters were refined together with all multipolar parameters except $\kappa^{\prime}$ of the $\mathrm{H}$ atoms. At each step the refinement was cycled until convergence. The H-atom coordinates were also shifted to neutron-diffraction values at each step and $\mathrm{H}$-atom isotropic displacement parameters were adjusted $\left(\sin \theta / \lambda<0.5 \AA^{-1}\right)$. During the refinement no extinction correction was deemed necessary. In the multipolar refinements, the multipole expansion was truncated at the octopole level for all non- $\mathrm{H}$ atoms and one single dipole centered on the $\mathrm{H}$ atom along the $\mathrm{C}(\mathrm{O}, \mathrm{N})-\mathrm{H}$ bond was calculated. Besides the constraint of electroneutrality of the unit cell, the $\mathrm{H}$ atoms $\mathrm{H} s p^{2}$ linked to $\mathrm{C}$ atoms $(\mathrm{CD} 1, \mathrm{CD} 2$, $\mathrm{CE} 1$ and $\mathrm{CE} 2)$ of the tyrosine group were assumed to have identical electron density deformations. At the end of the refinement, statistical factors were $R(F)=0.027$, $w R(F)=0.020\left[w=1 / \sigma^{2}(F)\right]$ and g.o.f. $=0.65$ for 10189 observed reflections $[I>2 \sigma(I)]$ and $N_{\text {par }}=544$; six reflections only had $\left(\left|F_{\text {obs }}\right|-\left|F_{\text {calc }}\right| / \sigma\right)>3$. The results of a rigid-bond test are excellent, as shown in Table 2. It is 


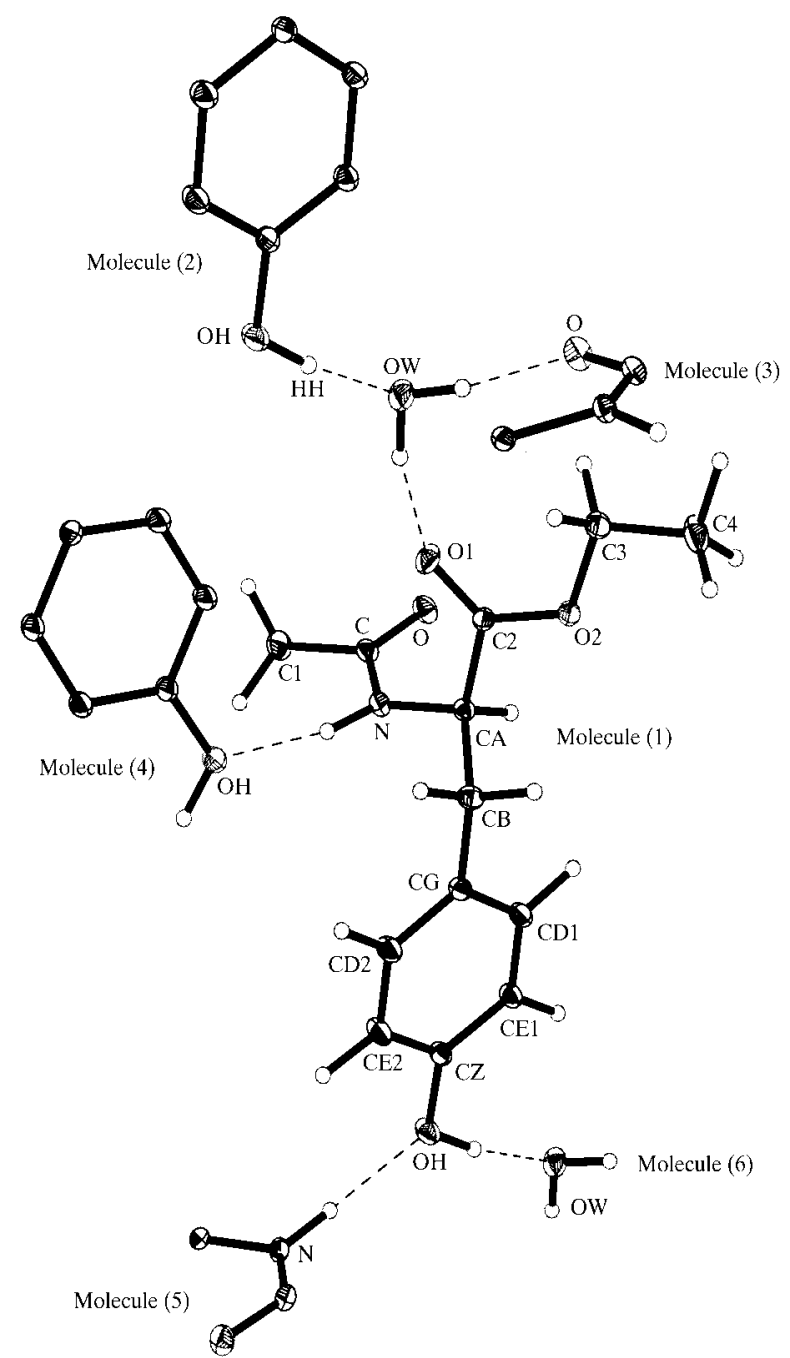

Fig. 1. ORTEP (Johnson, 1976) view of the packing of $\mathrm{C}_{13} \mathrm{H}_{17} \mathrm{NO}_{4} \cdot \mathrm{H}_{2} \mathrm{O}$ with $50 \%$ probability displacement ellipsoids for non- $\mathrm{H}$ atoms. Symmetry codes: molecule (1) $x, y, z$; molecule (2) $x, 1+y, z$; molecule (3) $-\frac{1}{2}+x, \frac{1}{2}-y, 1-z$; molecule (4) $-x, \frac{1}{2}+y, \frac{1}{2}-z$; molecule (5) $-x,-\frac{1}{2}+y, \frac{1}{2}-z$; molecule (6) $x,-1+y, z$. Hydrogen bonds are indicated by dotted lines.

therefore clear that electron density parameters are deconvoluted from the displacement parameters. The low values of the g.o.f. at high order and at the end of the multipolar refinement show that all low- or high-resolution frames are integrated in the same way and the experimental s.u.'s are uniformly overestimated by the data reduction program SAINT. This underestimated weighting scheme may have some effect on tiny details of the deformation density. $P_{v}, \kappa, P_{l m}$ and $\kappa^{\prime}$ parameters of the converged model have been deposited as supplementary material. $\dagger$

$\dagger$ See deposition footnote on p. 227.

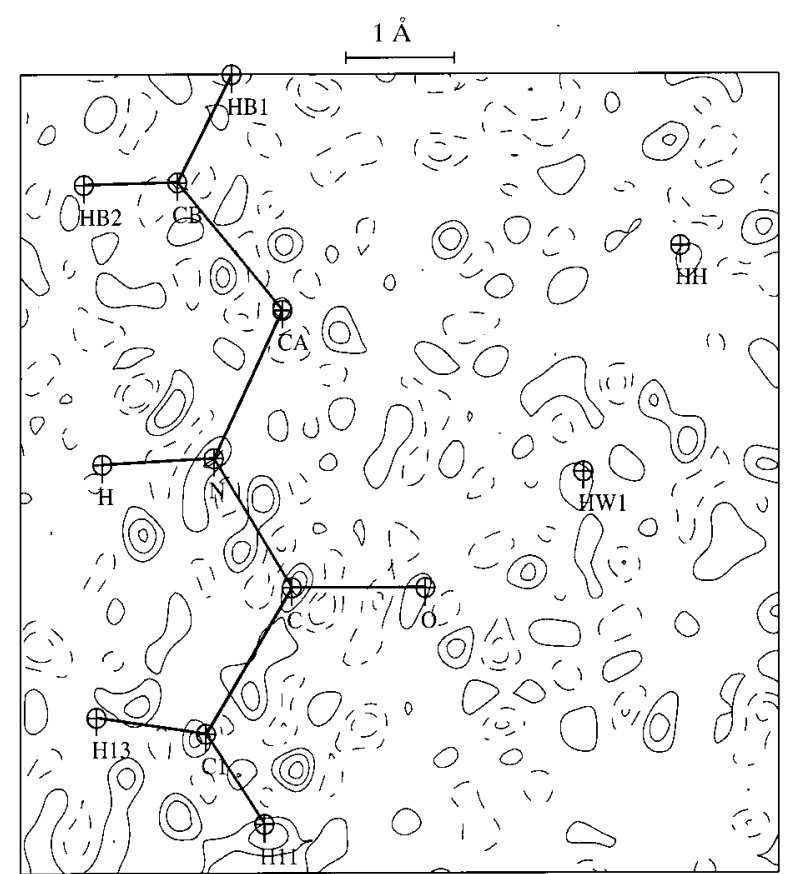

(a)

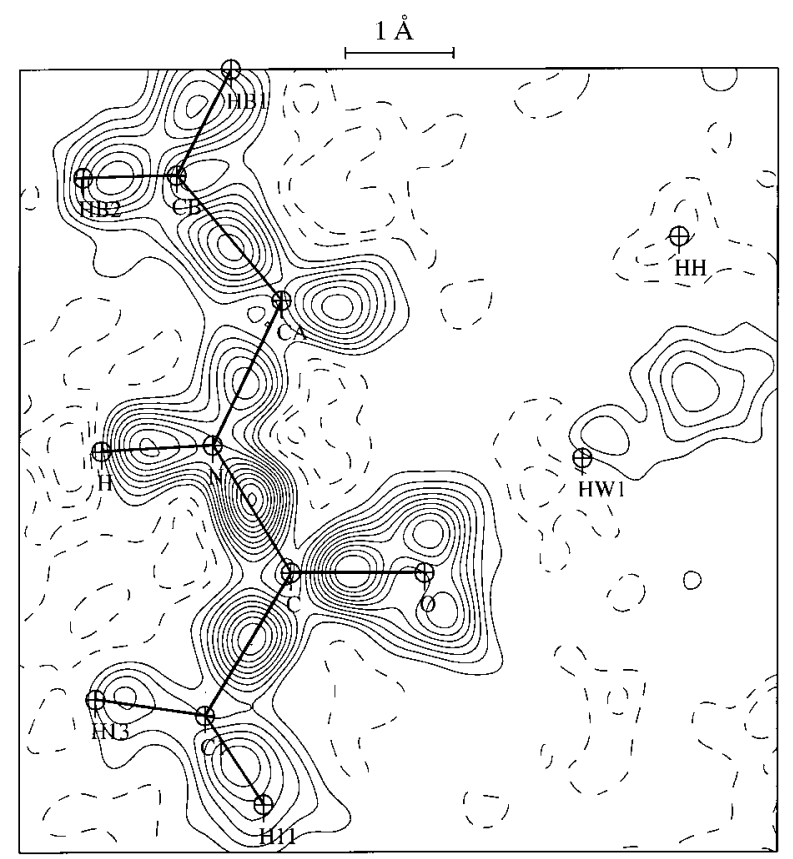

(b)

Fig. 2. (a) Residual density of the peptide bond. Non-zero contours are shown at intervals of $0.05 \mathrm{e}^{-3}$, negative contours are dashed. The residual density map is calculated by Fourier synthesis according to $\Delta \rho_{\text {res }}(\mathbf{r})=(1 / V) \sum_{\mathbf{H}}\left[\left|F_{\text {obs }}(\mathbf{H})\right|-\left|F_{\text {mul }}(\mathbf{H})\right|\right] \exp \left[i\left(\varphi_{\text {mul }}-2 \pi \mathbf{H} . \mathbf{r}\right)\right]$.

(b) Experimental deformation density of the peptide bond calculated by Fourier synthesis according to $\Delta \rho_{\exp }(\mathbf{r})=$ $(1 / V) \sum_{\mathbf{H}}\left[\left|F_{\text {obs }}(\mathbf{H})\right| \exp \left(i \varphi_{\text {mul }}\right)-\left|F_{\text {sph }}(\mathbf{H})\right| \exp _{\AA^{-3}}\left(i \varphi_{\text {sph }}\right)\right] \exp (-2 \pi i \mathbf{H} . \mathbf{r})$. Contours are shown at intervals of $0.05 \mathrm{e}^{-3}$. 


\section{Discussion}

Fig. 1 gives an ORTEP (Johnson, 1976) view of the local molecular packing. A critical examination of the residual density maps calculated for all data with $I>2 \sigma(I)$ permits discussion of the quality of the X-ray measurements and refinements. For example, Fig. 2(a) gives the residual experimental deformation density calculated in the peptide-link plane. Fig. $2(a)$ does not show any contour greater than $0.1 \mathrm{e}^{-3}$ [i.e. typically twice the estimated deformation electron density standard uncertainty in the unit cell: internal and external estimates of the average error in the experimental deformation maps (Cruickshank, 1949) are 0.08 and $0.05 \mathrm{e}^{-3}$, respectively], indicating that the noise level in the experimental data is low and confirming the high quality of the data.

The experimental deformation density in the same peptide-link plane as in Fig. 2(a) is given in Fig. 2(b). It is calculated using 7129 observed reflections with $\sin \theta / \lambda<$ $0.9 \AA^{-1}$ and $I>2 \sigma(I)$. The bonding density in the $\mathrm{C}-\mathrm{N}$, $\mathrm{C}-\mathrm{C} 1$ and $\mathrm{C}-\mathrm{O}$ bonds is $0.60(5), 0.50(5)$ and 0.55 (5) e $\AA^{-3}$, respectively, and the O-atom lone pair is clearly observed. The average bonding density for the $\mathrm{C}-\mathrm{C}$ bonds of the tyrosine group is $0.60(5) \mathrm{e} \AA^{-3}$. These results agree quantitatively with previous X-ray diffraction studies and with ab initio SCF deformation density maps (Stevens et al., 1978; Swaminathan et al., 1984; Lecomte et al., 1992; Souhassou et al., 1991, 1992). The experimental deformation density of the ester group and water molecule is also very well resolved and resembles those obtained for other peptides.

\section{Conclusion}

Precise electron density in molecular compounds can now be obtained with excellent accuracy in a much shorter time by using high-resolution low-temperature X-ray diffraction data from a CCD area detector. This will allow us to build a complete data bank of transferable experimental electron density parameters (i.e. aspherical scattering factors) for structures of lower resolution in the very near future.

\section{References}

Allen, F. H. (1986). Acta Cryst. B42, 515-522.

Blessing, R. H. (1987). Crystallogr. Rev. 1, 3-58.
Busing, W. R. \& Levy, H. A. (1964). Acta Cryst. 17, 142-146. Coppens, P. (1997). XI Sagamore Conference, Prince Albert, Canada, Abstract RA52, 65.

Creagh, D. C. \& McAuley, W. J. (1992). International Tables for Crystallography, Vol. C, edited by A. J. C. Wilson, pp. 206222. Dordrecht: Kluwer Academic Publishers.

Cruickshank, D. W. J. (1949). Acta Cryst. 2, 65-82.

Dahaoui, S., Jelsch, C., Howard, J. A. K. \& Lecomte, C. (1998). BCA Spring Meeting, St Andrews, Scotland, 5-8 April. Abstract CP-7.

Graafsma, H., Souhassou, M., Puig-Molina, A., Harkema, S., Kvick, Å. \& Lecomte, C. (1998). Acta Cryst. B54, 193-195.

Hansen, N. K. \& Coppens, P. (1978). Acta Cryst. A34, 909-921.

Hirshfeld, F. L. (1976). Acta Cryst. A32, 239-244.

Jelsch, C., Pichon-Pesme, V., Lecomte, C. \& Aubry, A. (1998). Acta Cryst. D54, 1306-1318.

Johnson, C. K. (1976). ORTEPII. Report ORNL-5138. Oak Ridge National Laboratory, Tennessee, USA.

Kabsch, W. (1993). J. Appl. Cryst. 26, 795-800.

Kirschbaum, K., Martin, A. \& Pinkerton, A. A. (1997). J. Appl. Cryst. 30, 514-516.

Koritsanszky, T., Flaig, R., Zobel, D., Krane, H.-G., Morgenroth, W. \& Luger, P. (1998). Science, 279, 356-358.

Lecomte, C., Ghermani, N., Pichon-Pesme, V. \& Souhassou, M. (1992). J. Mol. Struct. 255, 241-260.

Pichon-Pesme, V., Lecomte, C. \& Lachekar, H. (1995). J. Phys. Chem. 99, 6246-6250.

Pieret, A. F., Durant, F., Germain, G. \& Koch, M. (1972). Cryst. Struct. Commun. 1, 75-77.

Pinkerton, A. A. (1997). XI Sagamore Conference, Prince Albert, Canada, Abstract RM50, 63.

Sheldrick, G. M. (1990). Acta Cryst. A46, 467-473.

Sheldrick, G. M. (1993). SHELXL93. Program for the Refinement of Crystal Structures. University of Göttingen, Germany.

Sheldrick, G. M. (1996). SADABS. Siemens Area Detector Absorption Correction Program. University of Göttingen, Germany.

Siemens (1995). ASTRO and SAINT. Data Collection and Processing Software for the SMART System. Siemens Analytical X-ray Instruments Inc., Madison, Wisconsin, USA.

Soriano-García, M. (1993). Acta Cryst. C49, 96-97.

Souhassou, M., Lecomte, C., Blessing, R. H., Aubry, A., Rohmer, M. M., Wiest, R., Bénard, M. \& Marraud, M. (1991). Acta Cryst. B47, 253-266.

Souhassou, M., Lecomte, C., Ghermani, N., Rohmer, M. M., Wiest, R., Bénard, M. \& Blessing, R. H. (1992). J. Am. Chem. Soc. 114, 2371-2382.

Stevens, E. D., Rys, J. \& Coppens, P. (1978). J. Am. Chem. Soc. 100, 2324-2329.

Swaminathan, S., Craven, B. M., Spackman, M. A. \& Stewart, R. F. (1984). Acta Cryst. B40, 398-404. 